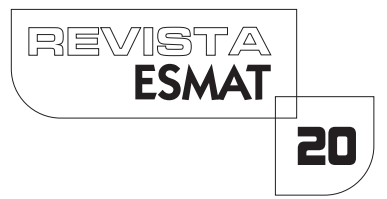

\title{
DIREITO COMPARADO: BRASIL, BÉLGICA E ARÁBIA SAUDITA FRENTE AOS DIREITOS DA MULHER
}

COMPARATIVE LAW: BRAZIL, BELGIUM AND SAUDI ARABIA ON WOMEN RIGHTS

LÍDIA JOY PANTOJA MOURA ${ }^{1}$

JULIANA COELHO DOS SANTOS ${ }^{2}$

DOUGLAS VERBICARO SOARES ${ }^{3}$

\section{RESUMO}

O presente trabalho possui uma análise a respeito dos direitos da mulher, como garantias e direitos fundamentais constitucionais e presentes na maioria das constituições dos Estados, tais quais: Brasil, Bélgica e Arábia Saudita. Consequentemente, a investigação apresenta um estudo acerca do direito comparado, sendo possível analisar a formação jurídica dos Estados em tela. Foi realizada uma investigação bibliográfica e uso do direito comparado para a metodologia do estudo. A investigação conclui pela existência de ideais preconceituosos e discriminatórios em relação às mulheres nesses três países, que vêm discriminando, ao longo dos tempos, essas pessoas em decorrência do gênero.

PALAVRAS-CHAVE: Direitos da Mulher; Direito Internacional; Direitos Humanos.

\section{ABSTRACT}

This paper has an analysis of women's rights, such as guarantees and fundamental constitutional rights and present in most state constitutions, such as Brazil, Belgium and Saudi Arabia. Consequently, the research presents a study on comparative law, it is possible to analyze the legal formation of states on screen. A bibliographic investigation was carried out for the methodology of the study. The investigation concludes by the existence of prejudiced and discriminatory ideals in relation to women in these three countries, which has been discriminated, over time, these people as a result of gender.

KEYWORDS:Women rights; International law; Human rights.

\footnotetext{
${ }^{1}$ Discente do curso de Direito da Universidade Federal de Roraima. Email: lidiajoypantojamoura@gmail.com.

${ }^{2}$ Mestranda em Direitos Humanos e Meio Ambiente pelo Programa de Pós-graduação em Direito da Universidade Federal do Pará (UFPA). Pós-graduanda em Direito Público com ênfase em gestão pública pela Faculdade Damásio. Graduada em Direito pelo Centro Universitário do Estado do Pará (CESUPA). Advogada. Email: juliannacoelho@hotmail.com.

${ }^{3}$ Doutor em Pasado y Presente de los Derechos Humanos e Mestre em Estudios Interdisciplinares de Género en la Especialidad, ambos pela Universidade de Salamanca. Integra como pesquisador os grupos de pesquisas $(\mathrm{CNPq})$ : Núcleo de Estudos e Pesquisas Ovelário Tames/NEPOT (UFRR); Consumo e Cidadania (UFPA); Consumo Responsável e Globalização Econômica (CESUPA). Atua como Coordenador do Núcleo de Prática Jurídica e Direitos Humanos - NPJ na Universidade Federal de Roraima e professor do magistério superior no Curso de Direito - UFRR. Email: douglas_verbicaro@yahoo.com.br.
} 


\section{INTRODUÇÃO}

Para ser conduzido o estudo serão observadas possibilidades para alcançar os princípios de igualdade e dignidade da pessoa humana no contexto dos direitos da mulher. Por outro lado, pode-se traçar discussões a respeito da emergência dos movimentos feministas decorrente da própria necessidade das lutas e reivindicações das mulheres (em busca de um reconhecimento de seus direitos dentro da sociedade, assim como pela legitimação de sua história), trazendo perspectivas mais animadoras em termos de futuro.

Supõe-se que a desvalorização da mulher é um fenômeno social arraigado à cultura do patriarcado (PROBST, 2003). Deste modo, para entender sobre esse fenômeno, torna-se necessário um estudo do contexto histórico para identificar a definição de gênero e as relações entre homens e mulheres (CARDOSO; ZIMMERMANN, 2020, p.144), bem como a delimitação de determinados conceitos, como por exemplo: o patriarcado ou o machista de submissão impositiva (VERBICARO SOARES, 2019, p.136), no qual podem ser encontradas as primeiras manifestações na organização da sociedade, baseadas numa relação de poder e dominação, entre mulheres e homens (BUSTOS, 2006, p. 2).

Sendo assim, atendo-se apenas à consagração dos Direitos Humanos no mundo, questiona-se: a eficiência da aplicação dos direitos das mulheres. Segundo a Organização das Nações Unidas (ONU) são direitos da mulher a liberdade sexual, a vida, liberdade de pensamento, privacidade, benefício do progresso científico (GOVERNO DO ESTADO, 2020), dentre outros. É certo dizer que a ONU e outras organizações internacionais já realizam, de certo modo, intervenções internacionais em países, conclamando-os a agirem em conformidade com padrões globais de humanidade, de acordo com a Declaração Universal de Direitos Humanos.

É imperioso destacar que nos casos do Brasil e da Bélgica, esses direitos já foram consolidados - homens e mulheres são iguais perante a lei, logo possuem igualdade de direitos por tratarem os gêneros em termo do princípio da igualdade, em suas constituições, tais quais a Constituição Federal Brasileira de 1988 em seu artigo 5, inciso I (BRASIL, 1990), e a Constituição Belga no seu artigo 10, segunda parte (BÉLGICA, 2019).

No entanto, a questão é mais profunda pois a aplicação dessa igualdade nos países em questão depende da atuação governamental e do aspecto cultural, que ainda não é uma realidade 
vivida pelas mulheres. Sendo assim, é possível observar a diferença entre os países, enquanto a Bélgica tem formações de influência internacional. A Arábia Saudita é exemplo de país com menor liberdade para as mulheres, ou até mesmo a simples igualdade de gênero, é possível analisar que após a pressão internacional e do próprio país começam a se discutir agora os direitos das mulheres.

Para fins de comparações jurídico-críticas, é necessário que haja o uso do direito comparado para promover uma análise das evoluções e retrocessos legislativos acerca do tema em tela. A Bélgica, segundo estudo realizado pelo site da British Broadcasting Corporation $\mathrm{BBC}$, é um dos melhores países no mundo em questão de igualdade de gênero, tendo as melhores políticas públicas e legislação a respeito da proteção e igualdade para as mulheres (BBC, 2019).

Por outro lado, a Arábia Saudita é, a priori, o mais conturbado país para que se viva uma mulher, pois não traz nenhuma condição de igualdade, onde a mulher só pode exercer direito, até aqueles fundamentais, após autorização do seu marido (NETO, 2015). Destarte, tem o entendimento de que a ONU é o principal canal atualmente de fomento dos Direitos Humanos no âmbito internacional. Destarte, os interesses referentes aos direitos das mulheres são uma das partes importantes do papel dessa organização internacional:

Principais Documentos Internacionais para a Promoção dos Direitos das Mulheres e da Igualdade de Gênero Carta das Nações Unidas (1945); Declaração Universal dos Direitos Humanos (1948); Convenção Interamericana Sobre a Concessão dos Direitos Civis à Mulher (1948); Convenção sobre os Direitos Políticos da Mulher (1953); Convenções da OIT números 100, 103, 111, 156, 171; Convenção sobre a Eliminação de Todas as Formas de Discriminação Racial - CERD (1966); Convenção Americana de Direitos Humanos, São José (1969); I Conferência Mundial sobre a Mulher (Cidade do México, 1975); Convenção Para Eliminar Todas as Formas de Discriminação Contra a Mulher - CEDAW de 1979 (OBSERVATóRIO DE GÊNERO, 2020).

No contexto da União Europeia, onde a Bélgica está inserida, também, foram adotados instrumentos para combater a violência e a discriminação contra as mulheres em outros países. E nessa conjuntura busca regularmente a questão dos direitos das mulheres e leis e práticas discriminatórias contra elas em seus contatos com outros países (NETO, 2015). Em contrapartida, a Arábia Saudita permitiu recentemente, em decisão do governo saudita no dia 02 de agosto de 2019, que mulheres adultas viajassem sem a permissão de um tutor e lhes concedeu mais controle sobre os assuntos da família, restringindo os poderes do chamado sistema de tutela masculina (FOLHA DE SÃO PAULO, 2019). 
É importante ressaltar que com o uso do direito comparado se podem notar as diferenças jurídicas quando, por exemplo, nas alterações feitas pelo Governo da Arábia Saudita que condizem com modificações no status civil e nos sistemas de documentos de viagem, reconhecendo que uma mulher pode ser chefe de família e permitindo que ela solicite um passaporte sem o consentimento do tutor, como estava em vigor.

Para o trabalho foi pensada uma pesquisa multidisciplinar, dando destaque às ciências sociais em busca de explicações acerca do tema. $\mathrm{O}$ artigo foi divido em uma introdução e mais três partes principais, visibilizando a realidade de cada país analisado: Brasil, Bélgica e Arábia Saudita respectivamente, seguidos das considerações finais e referências. A investigação conclui pela existência de ideais preconceituosos e discriminatórios em relação às mulheres nesses três países, que estão em análise no presente estudo, ao longo dos tempos, essas pessoas em decorrência do gênero.

\section{NO CONTEXTO DO BRASIL: A CONSTITUIÇÃO FEDERAL DE 1988}

É importante mencionar que o conceito de gênero foi elaborado em meados dos anos 1970. Sendo utilizado inicialmente nos trabalhos da socióloga Ann Oakley, devido as tensões provocadas pela emergência do movimento político feminista (MACHADO, 2016), que denunciava e refletia sobre a opressão sexual, a luta entre os sexos e as classes sexuais, o que permitiu a reconstrução o próprio conceito de feminino (POSSAS, 2004).

Muito embora a Constituição Federal de 1988 tenha enfatizado em seus artigos $5^{\circ} \mathrm{e}$ inc. I, art. $7^{\circ}$ e art. 226, parágrafo 5 , a vedação de qualquer forma de discriminação entre homens e mulheres, a ideologia patriarcal continua subsistindo na esfera social. Inobstante a isso, as normas constitucionais supracitadas representaram grande avanço para os direitos das mulheres no Brasil (BRASIL,1990):

Art. $5^{\circ}$ Todos são iguais perante a lei, sem distinção de qualquer natureza, garantindo-se aos brasileiros e aos estrangeiros residentes no País a inviolabilidade do direito à vida, à liberdade, à igualdade, à segurança e à propriedade, nos termos seguintes:

I - homens e mulheres são iguais em direitos e obrigações, nos termos desta Constituição;

De acordo com o informativo do Instituto Brasileiro de Geografia e Estatística - IBGE (2018), a igualdade entre homens e mulheres no Brasil ainda não é absoluta. O estudo revela que a questão de gênero não é homogênea no país, eis que há uma intensa desigualdade entre os 
percentuais de homens e mulheres que trabalham fora de suas casas, que ocupam cargos públicos. Tal desigualdade é fruto de uma desvantajosa estrutura histórica em relação às mulheres (IBGE, 2018).

Contextualizando os dados do Informativo do IBGE (2018) percentualmente as mulheres são em cargos gerenciais: 36\%; Cargos ministeriais estatais:7,1\%; Policia Militar: 13,4\%; Cargos políticos: 10,5\%; Ensino Médio escolar: 57,3\%; Tempo dedicado aos afazeres domésticos, incluem-se no cálculo donas de casa e mulheres que possuem trabalhos fora de casa: 18\% (e os Homens têm 10\% do seu tempo destinado a afazeres domésticos); As mulheres que estão empregadas têm uma diferença de quase $10 \%$ a mais que os homens e ganham em média $\mathrm{R} \$ 542,00$ a menos que os homens.

No que cerne à Carta Magna brasileira, em especial no seu artigo $7^{\circ}$ sobre a proteção da mulher:

Art. $7^{\circ}$ São direitos dos trabalhadores urbanos e rurais, além de outros que visem à melhoria de sua condição social:

XX - proteção do mercado de trabalho da mulher, mediante incentivos específicos, nos termos da lei;

XXX - proibição de diferença de salários, de exercício de funções e de critério de admissão por motivo de sexo, idade, cor ou estado civil (BRASIL, 2015).

Nessa conjuntura, a Constituição brasileira também prevê a proteção da mulher no reconhecimento da igualdade no âmbito da sociedade conjugal: “Art. 226. A família, base da sociedade, tem especial proteção do Estado. $\S 5^{\circ}$ Os direitos e deveres referentes à sociedade conjugal são exercidos igualmente pelo homem e pela mulher" (BRASIL, 2015).

Para corroborar essa ideia sobre a importância do contexto familiar, Berenice Dias (2010, pág. 1) acredita que as novas formações familiares estão ligadas à emancipação feminina:

[...] longo calvário a que foram submetidas as mulheres até conseguirem alcançar, ao menos no plano constitucional, a tão esperada igualdade. [...] Hoje, [...] em face de sua independência pessoal e profissional, passou a exercer funções relevantes não só no âmbito da família, mas na própria sociedade (DIAS, 2010, p. 1).

A emancipação feminina é uma questão que impacta diretamente na vida de muitas mulheres e permite que estas conquistem cada vez mais espaço no mercado de trabalho, ampliando o seu papel na sociedade, antes adstrito somente ao âmbito privado (doméstico).Infelizmente, na conjuntura nacional, muitas dessas mulheres acabam sendo sobrecarregadas no desempenho de uma dupla jornada de trabalho: dentro e fora de casa, pois são 
as responsáveis pelo acúmulo de tarefas no âmbito familiar privado e público na realização de tarefas laborais no mercado de trabalho externo.

\subsection{Legislação específica dos direitos da mulher no Brasil}

Com influências do mundo moderno dadas por tratados, convenções e acordos internacionais e ainda, por manifestações internas de movimentos feministas, o Brasil, atualmente, possui diversas leis que visam dar tratamento igualitário às mulheres brasileiras, além de fazer valer a Carta Magna e seus princípios, tais quais, dignidade da pessoa humana, liberdade, igualdade, entre outros.

Para demonstrar alguns marcos jurídicos taxativamente relevantes para os direitos da mulher, Athena Bastos (2019) fez um apanhado legislativo brasileiro das principais normas específicas de direitos da mulher brasileira por meio de seus marcos nacionais:

Lei 9.504/1997: Estabelece normas para as eleições (BRASIL, 1997);

Lei 11.340/2006: Lei Maria da Penha, cria mecanismos para coibir a violência doméstica e familiar contra a mulher (BRASIL, 2006);

Lei no. 13.104/2015: Altera o art. 121 do Código Penal, para prever o feminicídio como circunstância qualificadora do crime de homicídio, e o art. 1o da Lei de Crimes Hediondos, para incluir o feminicídio no rol dos crimes hediondos (BRASIL, 2015);

Lei 13.718 de 2018 alterou o Código Penal para tipificar os crimes de importunação sexual, o que permitiu a punição de homens que se masturbarem ou ejacularem em mulheres em locais públicos (BRASIL, 2018).

No que concerne às conquistas das mulheres ao acesso a direitos e proteção contra o preconceito e discriminação, foi a partir da década de 1970 no Brasil, com o movimento feminista,teve-se a luta em prol dos direitos das mulheres, culminando décadas depois, na criação da Lei 11.340/2006 (BRASIL, 2006), mais conhecida como a Lei Maria da Penha que obteve grande repercussão social e foi considerada uma das normas mais democráticas que tivemos desde a promulgação da Constituição Federal de 1988. Com efeito, a Lei alterou os mecanismos de caráter preventivo-geral já existentes no art. $129, \S 9^{\circ}$, do Código Penal, aumentando a pena. 
E ainda, mesmo com a criação da Lei Maria da Penha, verifica-se, pelos noticiários que a violência contra a mulher no Brasil continua vitimando milhares de brasileiras, sendo algo enraizado, cultural, proveniente de uma sociedade machista e patriarcal, que continua sendo praticada em larga escala.

Em linhas gerais, o feminicídio - artigo 121, § 2º VI, CP e incluído pela Lei ${ }^{\circ} 13.104$, de 2015 (BRASIL, 2015), é o crime de homicídio praticado contra mulheres pela razão de serem mulheres. Nas palavras de Montenegro, o feminicídio é o resultado do comportamento de desprezo pela condição do ser de sexo feminino, concretizado por condutas comissivas ou omissivas que vulnerem ou eliminem a vida (MONTENEGRO, 2015, p. 90).

Com a criação do neologismo feminicídio, o conceito de feminicídio é considerado mais amplo, pois inclui tanto as mortes intencionalmente provocadas às mulheres quanto aos fatos que derivam de abortos clandestinos, de enfermidades que não são adequadamente tratadas pelo sistema de saúde (GUIMARÃES, MOREIRA, 2017 apud LAGARDE, p. 129).

Dentre outras medidas adotadas pelo Brasil, as normas jurídicas mencionadas revolucionaram as condições de igualdade e dignidade para as mulheres brasileiras. Tais mecanismos visam inibir, prevenir e punir a ocorrência de atos que menosprezem os direitos humanos referentes às mulheres etambém outras pessoas em situação de vulnerabilidade (VERBICARO SOARES, 2018, p.55). Para tanto, vale ressaltar algumas normas e entendimentos da Bélgica e da Arábia Saudita para ter um parâmetro de comparação.

\section{O DIREITO INTERNACIONAL APLICADO NO BRASIL}

No contexto internacional, distintas Organizações têm o intuito de promover a assistência aos países no mundo afim de levar direitos fundamentais a todos os seres humanos, para tais objetivos elaboram instrumentos de direito internacional, como, por exemplo, os tratados e acordos de direitos humanosentre países. No Brasil não é diferente, e quando o país assina e posteriormente e promulga no seu ordenamento jurídico algum desses instrumentos, fica responsável por cumprir os termos acordados. Na realidade dos direitos da mulher, existe a previsão de alguns dos principais documentos internacionais que vigoram no Brasil (BASTOS, 2019). 
Para corroborar essa argumentação pode-se explicitar: A Convenção Interamericana sobre a Concessão dos Direitos Civis à Mulher (1948); Convenção Interamericana para Prevenir, Punir e Erradicar a Violência Contra a Mulher - Convenção de Belém do Pará (1994); IV Conferência Mundial sobre a Mulher (Beijing, 1995) (VERBICARO SOARES, 2012, p. 36-7); Convenção e Recomendação da OIT sobre Trabalho Decente para as Trabalhadoras e os Trabalhadores Domésticos - n. 189 e da Recomendação sobre o Trabalho Doméstico Decente para as Trabalhadoras e os Trabalhadores Domésticos ( $\mathrm{n}^{\circ}$ 201), da Organização Internacional do Trabalho (CÂMARA DOS DEPUTADOS, 2017) e, também, os Princípios de Yogyakarta (2007), que tratam sobre questões de Direitos Humanos relacionadas a matérias de diversidade sexual e gênero.

Como previamente abordado, a Lei Maria da Penha surgiu a partir do pedido à Comissão Interamericana de Direitos Humanos por Maria da Penha, que por causa das agressõesque sofreu do seu até então marido, ficou tetraplégica, mas que no trânsito jurídico brasileiro não conseguiu apoio. Logo, a própria criação da Lei que combate a violência doméstica surgiu no contexto internacional, por pressão do direito internacional por meio dos tratados internacionais promulgados pelo Brasil.

No contexto do direito internacional, o Brasil é signatário da Convenção Americana sobre Direitos Humanos (1969) desde 1992, a qual foi promulgada no país em 06 de novembro do referido ano, através do Decreto $\mathrm{n}^{\circ}$ 678. O Brasil também reconheceu a competência contenciosa da Corte Interamericana de Direitos Humanos em 1998, por meio do Decreto Legislativo $\mathrm{n}^{\circ} 89$ (BRASIL, 1992).

Em 1994, a Assembleia Geral da Organização dos Estados Americanos - OEA aprovou a Convenção Interamericana para Prevenir, Punir e Erradicar a Violência Contra a Mulher, conhecida como Convenção de Belém do Pará, sendo promulgada no Brasil pelo Decreto $\mathrm{N}^{\circ}$ 1.973 , de $1^{\circ}$ de agosto de 1996. Este instrumento foi ratificar no Brasil em 27 de novembro de 1995 (BRASIL, 1996).

Com isso, foram emitidas recomendações ao Estado brasileiro,para uma atenção especial nos casos envolvendo violência contra a mulher. Assim,fortalecendo o sentido de dar prosseguimento e, também, intensificar o processo de reforma que evite a tolerância estatal e o tratamento discriminatório com respeito à violência de gênero contra mulheres no Brasil. As recomendações orientam que o Estado promova medidas de capacitação e sensibilização dos 
funcionários judiciais e policiais especializados, para que compreendam a importância de não tolerar a violência de gênerocontra a mulher.

\subsection{Bélgica e sua Constituição}

Em 18 de abril de 1951, seis países europeus, incluindo Bélgica, assinaram o Tratado de Paris que criou a Comunidade Europeia do Carvão e do Aço (CECA), surgindo daí, um processo de cooperação e integração entre esses seis países da Europa. No dia 25 de março de 1957, esses países firmaram em Roma os Tratados que instituíram a Comunidade Econômica Europeia (CEE) e a Comunidade Europeia da Energia Atômica (Euratom), conhecidos como tratados de Roma, formando assim a União Europeia - UE (MACEDO; SANTOS, 2009).

Mas, na Bélgica possui sua própria Carta Magna que discorre sobre direitos fundamentais. O artigo 10 da Constituição Belga afirma que homens e mulheres são iguais perante a lei, ou seja, todos os direitos e deveres são aplicados a todos sem distinções de gênero. Não é certeza de que as mulheres tenham real liberdade e aceitação, há ainda casos de violência de gênero, dificuldades trabalhistas, mas juridicamente o país se encontra bem amparado.

Como a maior parte dos direitos decorre das ações da União Europeia, em suma,das decisões do Tribunal de Justiça das Comunidades Europeias (TJCE) demonstram o interesse dos países membros de promover a igualdade entre homens e mulheres, a exemplo da entrada da Turquia na UE, em 2002, que foi condicionada à realização de reformas legislativas no país, tais como a promulgação de lei que promovesse a igualdade entre homens e mulheres (MACEDO; SANTOS, 2009).

\subsubsection{Legislação belga específica dos direitos da mulher}

Por ser um país com certa estrutura jurídica de proteção, a Bélgica é considerada um país de refúgio, sendo grande acolhedora de mulheres que fogem dos seus países de origem, que não lhe dão condição mínima de existência (BBC, 2019). A questão dos direitos da mulher tem recebido crescente atenção nas últimas décadas, principalmente após a organização da Quarta Conferência Mundial sobre as Mulheres em Pequim, em 1995. A promoção e proteção dos direitos das mulheres é uma prioridade para a Bélgica e a União Europeia. 
Uma cartilha produzida pela European Commission (2012) trouxe alguns direitos fundamentais que tratam de forma igualitária homens e mulheres mas,mas, demonstra um detalhe interessante que diversas vezes o artigo mostra: que as leis são feitas para homens e mulheres, exceto quando fala sobre direitos específicos para a mulher, tais como prestações de licença maternidade, que oferece às mulheres uma quantia enquanto passam o período pós-parto resguardando o momento com seu filho. Ressalta-se nesse caso que há prévias determinações legais de contribuições para gozar do benefício, o tempo estimado pós-parto para a mulher corresponde a 15 ou 17 semanas quando parto múltiplo, ou seja, parto de gêmeos. (EUROPEAN COMMISSION, 2012).

Uma ação interessante foi que a Bélgica começou a oferecer cursos para explicar a todos os que precisam de asilo que devem se comportar, respeitosamente, em relação às mulheres, conforme o anunciodo secretário de Estado para Asilo e Imigração, após relatos de agressões sexuais na Alemanha em determinadas festas comemorativas (BICA; MACEDO; MARQUES et al, 2016)

Como a Bélgica firmou o direito ao voto para mulheres em 1948, a situação política é estável, mas a quantidade de mulheres em cargos políticos é menor que a de homens. Outra norma legislativa belga dita que qualquer pessoa que assediar alguém nas ruas da Bélgica poderá ser condenada a quase um ano de prisão ou a pagar uma multa que varia de 50 a 1000 euros. Uma nova lei foi aprovada na Bélgica em 2010(BICA; MACEDO; MARQUES et al2016), que proíbe o uso do véu islâmico integral em espaços públicos está de acordo com o Convênio Europeu de Direitos Humanos o que foi muito questionado por outros países principalmente pelo ideal da liberdade religiosa.

\subsubsection{Tratados internacionais vigentes na Bélgica}

Como o país faz parte da União Europeia, que mesmo tendo foco econômico,possui diversas influências nas decisões de igualdade entre homens e mulheres e na assinatura de acordos e tratados internacionais. Então a Bélgica é ativa internacionalmente no combate à violência contra mulher, desigualdades trabalhistas além formar princípios sólidos de dignidade da pessoa humana, liberdade e igual de gênero (MACEDO; SANTOS, 2009). 
Em 1979, foi adotada a Convenção das Nações Unidas (ONU) sobre a Eliminação de Todas as Formas de Discriminação contra as Mulheres, ratificada pela Bélgica em 1985. Este instrumento insiste na não discriminação em educação, emprego, atividades econômicas e sociais, assim como direitos e responsabilidades iguais de mulheres e homens em relação à paternidade. Também atribui grande importância aos direitos reprodutivos das mulheres, bem como ao acesso ao planejamento familiar e aos serviços sociais para conciliar maternidade e paternidade com a vida profissional (UNIVERSITY OF MINNESOTA, s.n).

Os Estados também são incentivados a combater práticas e estereótipos tradicionais que têm um impacto negativo nos direitos das mulheres, inclusive por meio da educação. Eles também são incentivados a adotar medidas de discriminação positiva contra as mulheres e a abolir o tráfico e a exploração da prostituição. A Assembleia Geral da ONU também adotou em 1993 uma Declaração sobre a Eliminação da Violência contra as Mulheres (MACEDO; SANTOS, 2009).

A Bélgica faz parte de diversos tratados e acordos internacionais que tratam dos direitos da mulher, em suma os principais documentos internacionais que também foram assinados pelo Brasil e já mencionados anteriormente. É muito provável que pelas condições em que a Bélgica se encontra juridicamente amparada, seja um país alvo de imigrantes mulheres que fogem de situações difíceis que passam em seus países como é o caso das mulheres árabes.

\section{A REALIDADE DA ARÁBIA SAUDITA}

São internacionalmente reconhecidas as restrições presentes no ordenamento jurídico da Arábia Saudita às mulheres, em especial restrições baseadas na religião. A religião oficial do país é o Islamismo, que tem como base o alcorão, livro que conta a história de Maomé (Muhammad), que fala sobre o deus Alá, e se assemelha com os ditos da Bíblia evangélica, esse texto se comparado a outros ordenamentos se assemelha a uma constituição. Com isso, se formou a Sharia ou Xaria que é o ordenamento jurídico árabe, o qual propõe interpretações diferentes de acordo com as esferas sociais (SOUZA, 2015).

De acordo com Neto (2016),à luz da legislação brasileira e de pactos internacionais, vários direitos são violados como a dignidade da pessoa humana, a livre manifestação de consciência e crença, direito de ir e vir, exercício do poder familiar, liberdade sexual, direito de 
herança, contrair matrimônio, proibindo e punindo a corrupção de menores, pena de morte, lesão corporal, etc.

No contexto do estudo deste artigo, mesmo que no alcorão não haja versículos que estabeleçam desigualdades entre homens e mulheres, é possível notar que a mulher tem uma imagem a "zelar" e o dever de ser submissa. Para exemplificar, há uma passagem no alcorão que traz a normativa que a mulher deve se vestir com pudor, por esse motivo as mulheres árabes usam burca - vestimenta que cobre todas as partes do corpo feminino deixando apenas os olhos à mostra (SOUZA, 2015, s.p).

\subsection{Leis novas aprovadas no contexto saudita}

Com o decorrer dos anos, algumas pressões internas e externas o país começou a fazer novas formulações legislativas, dentre elas a população da Arábia Saudita presenciou no mês de agosto de 2015 um feito inédito: o processo de registro de mulheres para concorrer a cargos políticos nas eleições locais, que ocorreram em dezembro deste mesmo ano. Adicionalmente, as mulheres alcançaram o almejado sufrágio e puderam depositar seus votos para eleger seus líderes municipais.

$\mathrm{Na}$ educação, as mulheres dependem totalmente da aprovação de um responsável masculino para estarem na Arábia Saudita ou em outro país.Em julho de 2017, as escolas para meninas começaram a ter educação física de acordo com a lei Sharia, além disso, o país já conta várias universidades para mulheres. No mesmo sentido, o príncipe Mohamed Bin Salman, em junho de 2017, elaborou um plano denominado de "Visão 2030", que tem a perspectiva de aumentar a taxa de emprego das mulheres de $22 \%$ a $30 \%$ em uma década, no contexto econômico do país. (ESTADO DE MINAS, 2019).

Em agosto de 2019, foi permitido que as mulheres pudessem ter passaporte sem acordo prévio do tutor masculino, lembrando que em 2018 as mulheres foram autorizadas a dirigir pela primeira vez na história do país. Mesmo com o avanço, não há que falar em uma iniciativa de novas liberdades políticas. De acordo com o jornal digital Estado de Minas (2019) algumas ativistas " $[\ldots]$ das quais algumas das quais haviam lutado durante anos pelo direito de dirigir, foram detidas e julgadas, principalmente por ter falado com jornalistas estrangeiros". Essa abordagem permite uma análise mostrando que mesmo após novas concepções do ordenamento 
jurídico saudita e ainda há grandes dificuldades culturais de aceitação da igualdade da mulher (SOUZA, 2015, s.p).

No sentido familiar, a mulher está sujeita à autorização do tutor para casar e também a casamentos arranjados, podendo o marido se divorciar sem autorização da mulher.Então o Ministério da Justiça (2018) deu sugestão de que os tribunais avisem as mulheres afim de informar o divórcio, isso por mensagem de texto. Ainda em 2018, pela primeira vez foram autorizadas a estarem em eventos esportivos com a regra de que estejam em arquibancadas separadas, e reduziu os poderes da polícia religiosa que repreendia mulheres que utilizam as unhas cintilantes ou não suficientemente cobertas (ESTADO DE MINAS, 2019).

Por fim, sob as novas emendas, mas mulheres maiores de 21 anos têm os mesmos direitos que os homens, nos termos da lei, em relação a viagens (FOLHA DE SÃO PAULO, 2019). Pela primeira vez, as emendas concedem às mulheres o direito de registrar nascimentos, casamento, divórcio e emitir documentos familiares oficiais (NETO, 2015, s.p).

A Comissão dos Direitos Humanos Saudita é uma instituição criada com o objetivo de tratar das questões que envolvem direitos humanos, consequentemente os direitos da mulher, que foi estabelecida em 2008, deveria assegurar os direitos das mulheres, e também deveriam investigar casos de violação de direitos das mulheres, porém as investigações não têm sido levadas a sério (IQBAL, 2017 apud FREEDOM HOUSE, 2017, p. 75).

De certa forma, as recentes alterações legislativas demonstram uma demora no processo de busca pela igualdade entre os gêneros, mas a Arábia Saudita tem que se empenhado, dentre eles o direito da mulher de participar ativamente da vida política, conforme prevê o Pacto Internacional dos Direitos Civis e Políticos, de 1976, que devem dispor deste direito para que sejam capazes de se expressar politicamente diante dos avanços e problemas de suas sociedades (SOUZA, 2015, s.n).

Segundo a lei, a violência física e sexual pode ser punida com no mínimo um mês até um ano de prisão e multa de US\$13.300, sendo assim, a violência doméstica passou a ser punida a partir de 2013. Acusados reincidentes nesse crime podem ter suas sentenças dobradas. Para tanto, existe um Departamento para Prevenção de Abusos, em que se espera que tenha treinamento de como lidar com a questão do abuso doméstico, apesar desse crime não ser o foco do departamento, para isso, as vítimas de abuso têm direito a tratamento psicológico, médico e conciliação familiar, mas para terem acesso a esses serviços é necessária a aprovação do guardião. 
E ainda, o departamento, não recebe denúncias depois das 22 horas (IQBAL, 2017 apud PARLAMENTO EUROPEU, 2014, p. 75).

Com toda pressão interna por meio das manifestações e pela pressão externa internacional, o governo da Arábia Saudita tem tentado se ajustar na questão de igualdade entre homem e mulher, como já diante das novas leis e interpretações da Sharia, sendo necessária influência internacional, bem como, a importância do direito internacional frente a esses debates.

Para sedimentar a formação jurídico-religiosa da Arábia Saudita, Riffat Rêgolqbal (2017), dispõe:

\begin{abstract}
No senso comum e na mídia, a religião é frequentemente apontada como a causadora da desigualdade de gênero. No entanto, não podemos colocar a religião como proxy da cultura [...] É necessário discernir a religião em si dos seus fies conservadores, bem como das tradições que ultrapassam os séculos. Muitos aspectos culturais da região são anteriores até mesmo ao surgimento do islã, alguns deles foram mencionados no capítulo 3. Este trabalho procurou mostrar que a religião pode ser usada de diferentes maneiras para alcançar um fim. O feminismo islâmico ainda é considerado uma novidade no campo de estudo, não havendo ainda muitas pesquisas sobre o assunto, principalmente no ocidente (IQBAL, 2017, p. 88-9).
\end{abstract}

De acordo com Riffat RêgoIqbal(2017, p.88-9), os governantes do país estão cada vez mais abertos à normatização de direitos fundamentais das mulheres, se aproximando das ideologias culturais ocidentais. Assim, a aplicação desses novos direitos e novas ideologias favoráveis à dignidade da mulher promove a igualdade de gênero, mas é desafiadora, tendo em vista a cultura árabe fundamentada no islamismo, religião que dissemina o amor e não promove desigualdades, mas que, por meio de uma construção social, é interpretada de forma prejudicial à mulher árabe.

\title{
CONSIDERAÇÕES FINAIS
}

A situação jurídica dos países em estudo, em relação aos direitos das mulheres, demonstra que o direito comparado é uma ferramenta interessante para a análise de direitos considerados fundamentais à mulher em cada país e de que forma o Brasil se adequa às influências externas e aos atos feministas internos.

Para tanto, o estudo identificou diversas formações legislativas, bem como evidenciou que por mais que existam leis no país que visam coibir, prevenir e punir atos que afrontam a dignidade da mulher, ainda sim existem grandes números de violência contra a mulher, 
desigualdades trabalhistas, diferentes posicionamentos de acordo com o gênero que podem desaguar na economia, no direito, nas formações familiares, nas condições trabalhistas etc.

Por fim, é notória a diferença cultural de cada país e como cada um a seu próprio tempo começou a mudar suas ideologias. É certo que os movimentos feministas são muito influenciadores no ordenamento jurídico do país em que ocorrem, por outro lado, as pressões internacionais, forçam um avanço protecionista e que beneficia a mulher como sujeito de direito.

\section{REFERÊNCIAS}

BASTOS, Athena. Direitos da mulher: avanços legislativos e perspectivas do feminismo. Disponível em: <https://blog.sajadv.com.br/direitos-da-mulher/>. Acesso em 13 de junho de 2020.

BICA, Bruno; MACEDO, Marina; MARQUES, Joanna; CIROLINI, Isadora; HICKMANN, Maria Luisa.Situação das Mulheres na Bélgica. 2016. Disponível em: <https://prezi.com/uid6qyhbkwl/situacao-das-mulheres-na-belgica-e-na-turquia/>. Acesso em 13 de junho de 2020.

BÉLGICA. Constituição (1831). A Constituição belga: promulgada em 07 fevereiro de 1831. 2019. Disponível em: <https://www.senate.be/doc/const_fr.html>. Acesso em 12 de junho de 2020.

BRASIL. Constituição (1988). Constituição da República Federativa do Brasil: promulgada em 5 de outubro de 1988. 4. ed. São Paulo: Saraiva, 1990.

BBC. Dia Internacional da Mulher: os únicos seis paises que garantem direitos iguais a homens e mulheres. Disponível em: https://www.bbc.com/portuguese/internacional-47471950. Acesso em12 de junho de 2020.

BUSTOS, M. Ángeles. La mujer ante el siglo XXI: una perspectiva desde el ordenamiento jurídico-administrativo. Badajoz, Espanha: @becedario, 2006.

CÂMARA DOS DEPUTADOS. Legislação Informatizada - decreto legislativo $n^{\circ} 172$, de 2017 Convenção. Disponível em:

$<$ https://www2.camara.leg.br/legin/fed/decleg/2017/decretolegislativo-172-4-dezembro-2017785852-convencao-154384-

pl.html\#: :text=O\%20Congresso $\% 20 \mathrm{Nacional} \% 20$ decreta $\% 3 \mathrm{~A}, \mathrm{da} \% 20$ Organiza $\% \mathrm{C} 3 \% \mathrm{~A} 7 \% \mathrm{C} 3 \%$ A30\%20Internacional\%20do\%20Trabalho>.Acesso em12 de junho de 2020.

CARDOSO, Adriano; ZIMMERMANN, Tânia. Reflexões sobre gênero e homossexualidade em grafitos escolares. In.:Humanidades \& Tecnologia em Revista (FINOM) - ISSN: 1809-1628. Ano XIV, vol. 20, p. 142-158, Jan/jul, 2020. 
DIAS, Berenice. A Mulher e o Direito. Artigo de opinião. 2010. Disponível em:

$<$ http://www.mariaberenice.com.br/manager/arq/(cod2_732)23_a_mulher_e_o_direito.pdf $>$. Acesso em16 de junho de 2020.

ESTADO DE MINAS. Os direitos da mulher na Arábia Saudita: restrições e reformas. 2019.Disponívelem: $<$ https://www.em.com.br/app/noticia/internacional/2019/08/02/interna_intern acional,1074445/os-direitos-da-mulher-na-arabia-saudita-restricoes-e-reformas.shtml $>$. Acesso em13 de junho de 2020 .

MACEDO, Eunice; SANTOS, Sofia. Apenas mulheres? Situação das mulheres no mercado de trabalho em quatro paises europeus. 2009. Disponível em:

$<$ http://www.scielo.mec.pt/scielo.php?script=sci_arttext\&pid=S0874-55602009000100011>. Acesso em14 de junho de 2020.

EUROPEAN COMMISSION. Emprego, Assuntos Sociais e Inclusão - Os seus direitos de segurança social na Bélgica. 2012. Disponível em:

$<$ http://ec.europa.eu/social/main.jsp?langId=pt\&catId=815>. Acesso em13 de junho de 2020.

FOLHA DE SÃO PAULO. Publicação da matéria em: 02/08/2019. Disponível em:

$<$ https://www1.folha.uol.com.br/mundo/2019/08/mulheres-da-arabia-saudita-poderao-viajar-aoexterior-sem-autorizacao-de-homens.shtml> Acesso em12 de junho de 2020.

GOVERNO DO ESTADO. Direitos da Mulher. Disponível em:

$<$ http://www.justica.pr.gov.br/Pagina/Direitos-da-Mulher>. Acesso em 12 de junho de 2020.

GUIMARAES, Isaac N. B. Sabbá. MOREIRA, Romulo De Andrade. A Lei Maria da Penha: aspectos criminológicos, de política criminal e do procedimento penal. 4ed. Curitiba, Brasil: Juruá, 2017.

IBGE. Informativo sobre desigualdades entre homens e mulheres no Brasil do Instituto Brasileiro de Geografia e Estatística - IBGE (2018). Disponível em:

$<$ https://biblioteca.ibge.gov.br/visualizacao/livros/liv101551_informativo.pdf $>$. Acesso em $12 \mathrm{de}$ junho de 2020.

IQBAL, Riffat Rêgo. Monografia de conclusão de curso. As múltiplas faces da desigualdade de gênero no Oriente Médio: Uma análise comparativa entre a Arábia Saudita, o Líbano, os Emirados Árabes Unidos e o Catar. Universidade de Brasília - UnB Instituto de Relações Internacionais - IREL, Brasília. 2017. Disponível em:

$<$ https://bdm.unb.br/bitstream/10483/19933/1/2017_RiffatRegoIqbal.pdf>. Acesso em13 de junho de 2020.

MACHADO, Lia. Feminismos brasileiros nas relações com o Estado. Contextos e incertezas. In.: Cadernos Pagu. Campinas, Brasil, no 47, p. 5-40. 17 nov. 2016. Disponível em: <https://periodicos.sbu.unicamp.br/ojs/index.php/cadpagu/article/view/8647251/14200>. Acesso em10 de junho de 2020. 
MELO, Érica. Feminismo: velhos e novos dilemas uma contribuição de Joan Scott. Cadernos Pagu, (31), 553-564. Disponível em:

$<$ https://www.periodicos.sbu.unicamp.br/ojs/index.php/cadpagu/article/view/8644893>. Acesso em17 de junho de 2020.

MONTENEGRO, Marília. Lei Maria da Penha: uma análise criminológico-crítica. $1^{\text {a }}$ edição, 2015.

NETO, Geraldo. Arábia Saudita. Direito das Mulheres?. 2015. Disponível em:

https://geraldoneto.jusbrasil.com.br/artigos/261921990/arabia-saudita-direito-das-mulheres.

Acesso em12 de junho de 2020.

OBSERVATóRIO DE GÊNERO. Principais documentos Internacionais para promoção dos Direitos das Mulheres e da Igualdade de Gênero. Disponível em:

$<$ http://www.observatoriodegenero.gov.br/eixo/internacional/documentos-internacionais $>$.

Acesso em12 de junho de 2020.

BRASIL. Decreto no 678, de 6 de novembro de 1992. 1992. Disponível

em:<http://www.planalto.gov.br/ccivil_03/decreto/d0678.htm\#: :text=DECRETO\%20No\%2067

$8 \% 2 \mathrm{C} \% 20 \mathrm{DE}$,que $\% 201$ he $\% 20$ confere $\% 20 \mathrm{o} \% 20$ art>. Acesso em 12 de junho de 2020.

BRASIL. Decreto $n^{\circ} 1.973$, de $1^{\circ}$ de agosto de 1996. 1996. Disponível em:

$<$ http://www.planalto.gov.br/ccivil_03/decreto/1996/D1973.htm>. Acesso em13 de junho de 2020.

BRASIL. Lei $n^{\circ} 9.504$, de 30 de setembro de 1997. 1997. Disponível em:

$<$ http://www.planalto.gov.br/ccivil_03/leis/19504.htm>. Acesso em13 de junho de 2020.

BRASIL. Lei $n^{\circ} 11.340$, de 7 de agosto de 2006. 2006. Disponível em:

$<$ http://www.planalto.gov.br/ccivil_03/_ato2004-2006/2006/lei/111340.htm>. Acesso em13 de junho de 2020 .

BRASIL. Lei $n^{\circ} 13.104$, de 9 de março de 2015. 2015. Disponível em:

$<$ http://www.planalto.gov.br/ccivil_03/_ato2015-2018/2015/lei/113104.htm>. Acesso em13 de junho de 2020 .

BRASIL. Lei $n^{\circ} 13.718$, de 24 de setembro de 2018. 2018. Disponível em:

$<$ http://www.planalto.gov.br/ccivil_03/_Ato2015-2018/2018/Lei/L13718.htm>. Acesso em13 de junho de 2020 .

POSSAS. Lidia. Vozes femininas na correspondência de Plínio Salgado (1932-1938).In.: GOMES, Angela. Escrita Si. Escrita da História. Rio de Janeiro, Brasil: Editora FGV, 2004.

PRINCÍPIOS DE YOGYAKARTA. Principios sobre la aplicación de la legislación internacional de Derechos Humanos en relación con la orientación sexual y la identidad de género. 2007. Disponível

em: $<$ https://www.refworld.org/cgibin/texis/vtx/rwmain/opendocpdf.pdf?reldoc=y\&docid=48244e $9 f 2>$. Acesso em 10 de junho de 2020. 
PROBST, Elisiana. A evolução da mulher no mercado de trabalho. 2003. Disponível em: $<$ http://www.icpg.com.br/artigos/rev02-05.pdf $>$. Acesso em12 de junho de 2020.

SENADO. Artigo $7^{\circ}$. 2015. Disponível em:

$<$ http://www.senado.leg.br/atividade/const/con1988/CON1988_15.09.2015/art_7_.asp >. Acesso em12 de junho de 2020 .

SENADO. Artigo 226. 2015. Disponível em:

$<$ http://www.senado.leg.br/atividade/const/con1988/con1988_07.05.2015/art_226_.asp>. Acesso em12 de junho de 2020.

SCOTT, Joan Wallach. "Gênero: uma categoria útil de análise histórica". Educação \& Realidade. Porto Alegre, vol. 20, n² 2, jul./dez. 1995, pp. 71-99. Revisão de Tomaz Tadeu da Silva a partir do original inglês (SCOTT, J. W.. Gender and the Politics of History. New York: Columbia University Press, 1988. PP. 28-50.), de artigo originalmente publicado em: Educação \& Realidade, vol. 15, nº 2, jul./dez. 1990. Tradução da versão francesa (Les Cahiers du Grif, n $^{\circ}$ 37/38. Paris: Editions Tierce, 1988.) por Guacira Lopes Louro. Disponível em:

$<$ https://ia800903.us.archive.org/24/items/scott_gender/scott_gender.pdf $>$. Acesso em17 de junho de 2020 .

SOUZA, Matheus. Os direitos da mulher na Arábia Saudita: uma análise das concessões e proibições sob a ótica dos preceitos islâmicos. 2015. Disponível em:

$<$ https://pucminasconjuntura.wordpress.com/2015/12/10/os-direitos-da-mulher-na-arabia-sauditauma-analise-das-concessoes-e-proibicoes-sob-a-otica-dos-preceitos-islamicos/>.Acesso em 13 de junho de 2020 .

UNIVERSITY OF MINNESOTA; Human Rights Library. Ratification of International Human Rigths Treaties - Belgium. Disponível em: $<\mathrm{http}: /$ hrlibrary.umn.edu/research/ratificationbelgium.html $>$. Acesso em18 de junho de 2020 .

VERBICARO SOARES, Douglas. Las mujeres y las personas homosexuales en las Fuerzas Armadas. Especial referencia a las FFAA Brasileñas. Trabajo fin de Máster. Programa Estudios Interdisciplinares de Género y Políticas de Igualdade. Faculdade de Direito. Universidade de Salamanca - USAL, Salamanca, Espanha, 2012.146 p.

VERBICARO SOARES, Douglas. A condenação histórica da orientação sexual homossexual - as origens da discriminação à diversidade sexual humana: violações aos direitos sexuais - reflexos do Brasil Colônia ao século XXI. In.: Revista Latino-Americana de Direitos Humanos HENDU. Belém, Brasil, V. 7, I, pp. 50-64, 2018.

VERBICARO SOARES, Douglas. O estudo da orientação homossexual pensado nos Direitos Humanos e na sociedade brasileira. In.: Revista Bagoas - Estudos gays, gênero \& sexualidades. Natal, Brasil, V. 13, nº 20, pp.121-163, 2019.

Recebido em: 20/06/2020 Aprovado em: 27//0/2020 